${ }^{1}$ Mestrando em

Saúde Coletiva pela

Universidade Estadual

de Feira de Santana-

BA.

${ }^{2}$ Mestranda em

Saúde Coletiva pela

Universidade Estadual

de Feira de Santana-

BA.

${ }^{3}$ Professora titular da

Universidade Estadual

de Feira de Santana-

BA, no Departamento de Saúde.

${ }^{4}$ Professora adjunta

no Departamento de

Medicina Preventiva

e Social da Faculdade

de Medicina da

Bahia - Universidade

Federal da Bahia

e colaboradora

do Programa de

Pós-Graduação em

Saúde Coletiva da

Universidade Estadual

de Feira de Santana.

\section{REFLEXÕES SOBRE A SAÚDE DOCENTE NO CONTEXTO DE MERCANTILIZAÇÃO DO ENSINO
SUPERIOR RCANTILIZAÇÃO DO ENSINO
SUPERIOR}

REFLECTIONS ABOUT THE HEALTH OF TEACHERS IN THE CONTEXT OF COMMODIFICATION OF HIGHER EDUCATION

Daniel Alberto Santos e Santos ${ }^{1}$, Caroline Almeida de Azevedo², Tânia Maria de Araújo³, Jorgana Fernanda de Souza Soares ${ }^{4}$

\section{RESUMO}

As modificações sociopolíticas e econômicas intensificadas a partir da década de 1990 produziram diversas mudanças no âmbito do trabalho docente. O modelo de organização passou a exigir maior produtividade e qualificação profissional cada vez mais especializada, com base na acentuação do trabalho, provocando, assim, o surgimento de novas atribuições, as quais vêm repercutido negativamente na saúde desses profissionais. Nesse cenário, os docentes passam a conviver com um ambiente precarizado, regido pela lógica empresarial, levando a situações de sobrecarga, de estresse e de competição, além de fragilizar as relações interpessoais e dificultar o uso adequado do tempo livre, aspectos esses que comprometem a qualidade de vida dos docentes. Nesse contexto, e entendendo que a forma como as condições de trabalho são estruturadas 
desempenha papel crucial no processo saúde-doença ocupacional, o presente ensaio teórico tem como finalidade problematizar o processo de mercantilização nas universidades brasileiras e os efeitos desse processo na saúde docente.

Palavras-chave: Saúde. Docente. Ensino superior. Mercantilização.

\section{ASPECTOS INTRODUTÓRIOS}

As modificações sociopolíticas e econômicas de caráter neoliberal, que foram intensificadas, no Brasil, a partir da década de 1990, geraram mudanças substantivas nas características e condições do trabalho docente. O modelo de organização adotado privilegiou indicadores quantitativos de produtividade e qualificação profissional, produzindo situações de constante pressão e instabilidade no emprego. Com isso, o trabalho passou a apresentar, nesses moldes, traços de precarização (NECKEL; FERRETO, 2006).

A atividade docente, que sempre esteve associada aos desafios envolvidos nos processos de ensino-aprendizagem, sob a égide das relações sociais capitalistas, vem se caracterizando pela sobrecarga de tarefas, cuja execução demanda, cada vez mais, níveis de especialização elevados, longas e intensas jornadas de dedicação, múltiplos empregos e precarização das condições de trabalho e dos vínculos contratuais (MASCARENHAS, 2010). 
Como consequência, em especial para a educação superior brasileira, os sucessivos governos neoliberais implementaram uma reforma estrutural nas universidades por meio de um intenso processo de privatização que tem, dentre outros aspectos, afetado a organização do trabalho docente (MANCEBO; MAUÉS; CHAVES, 2006). Novas exigências somaram-se às demandas existentes, estruturando um novo perfil do docente na contemporaneidade e caracterizando o trabalho desse profissional em moldes de precarização, intensificação, flexibilização, aumento constante de produtividade e de acúmulo de funções (envolvendo ensino, pesquisa, extensão, orientação e gestão das próprias condições de trabalho). Essas características, em conjunto, têm representado impactos negativos sobre a saúde dos professores.

O presente ensaio teórico tem como finalidade problematizar o processo de mercantilização nas universidades brasileiras por meio de discussões sobre o conjunto de transformações ocorridas com a crise do capital e com a implantação das reformas educacionais, tomadas a partir da década de 1990, e discutir possíveis repercussões e/ou efeitos dessas mudanças na saúde docente.

\section{A UNIVERSIDADE E O TRABALHO REMODELADO DO ENSINO SUPERIOR: A MERCANTILIZAÇÃO DO ENSINO}

A universidade é uma instituição social comprometida com a formação de profissionais, técnicos e intelectuais de nível superior, para atender às crescentes demandas da sociedade 
em um dado contexto histórico. Tal instituição, no que tange à própria constituição, representa o quadro social da época em que existe, exerce o papel de manutenção ou transformação social, reflete o momento histórico e as diferentes forças sociopolíticas da realidade em que está inserida (CAMPOS; LOPES; FREITAS, 2004).

Assim, a universidade está interligada à sociedade e, como tal, transforma-se no tempo e no espaço (CAMPOS; LOPES; FREITAS, 2004). Um novo cotidiano vem se construindo nas universidades públicas brasileiras. O principal marco dessas mudanças surgiu a partir da crise de acumulação do capital, ocorrida em âmbito internacional, por volta do início da década de 1970, que teve como reflexos as transformações da sociedade de forma geral e, mais especificamente, nas relações de trabalho, a partir da adoção de uma lógica produtivista e/ou mercadológica (BOSI, 2007; MANCEBO, 2007).

Tal cenário foi desenhado pela falência do modelo fordista e da doutrina keynesiana, devido à fragilidade desses em fornecer soluções para os problemas desencadeados pelo regime de acumulação do capital e pelo avanço da exclusão social. Dessa forma, com a crise, iniciou-se um novo período, marcado pela alta dos preços em conjunção com entraves no ritmo de crescimento econômico em diversos países industrializados (MANCEBO; MAUÉS; CHAVES, 2006). Por conseguinte, buscouse redefinição das políticas econômicas, com o intuito de aplacar, mesmo que de forma temporária, a crise proveniente da desvalorização do dólar americano e do aumento acentuado do preço do petróleo. 
Como alternativa para se superar essa crise, foram estruturadas medidas que atuaram na destruição de parte dos meios de produção já existentes, no aumento da taxa de exploração sobre o trabalho e da expansão do capitalismo sobre ramos recém-submetidos ao modo de produção tipicamente capitalista (BOSI, 2007), incluindo as atividades relacionadas ao setor da saúde e da educação. Conformaram-se, desse modo, novas formas capitalistas de produção, tendo em vista a retomada do processo de reprodução e acumulação do capital; ou seja, tais atividades foram incorporadas ao circuito de produção capitalista (mercantilizadas) para funcionarem como elemento adicional aos investimentos de capital, que antes se encontravam estancados em função de insignificantes taxas de lucro (LUXEMBURG, 2003).

Além disso, surgem perspectivas, apoiadas no modelo de acumulação flexível, e imposições de reformas aos estadosnação, que passaram de interventores a gestores, ou seja, transferiram funções específicas do setor de serviços para o mercado, adotando a privatização como forma de superação dos problemas que afetavam suas economias e alterando significativamente a concepção das relações entre os setores públicos e privados (MANCEBO; MAUÉS; CHAVES, 2006).

Esse fenômeno se intensificou ao longo da década de 1990, com a implantação das políticas de ajustes neoliberais, em que as esferas públicas e privadas foram redefinidas nas variadas atividades humanas, no âmbito do Estado e da sociedade civil. Com isso, em diversas nações, desencadeou-se um processo de ampliação do espaço privado, com o argumento de que o Estado não apresentava condições sólidas de gerenciar 
diversos setores da economia. Assim, conquistas sociais, como o direito à educação, à saúde, ao transporte público, foram atividades transferidas para a iniciativa privada, fragilizando muitos direitos sociais conquistados pelas lutas da classe trabalhadora (MANCEBO; MAUÉS; CHAVES, 2006).

Como reflexo desse processo, ocorreram mudanças de natureza técnica e organizacional que promoveram transformações nas estruturas e funções das instituições de ensino superior (LIM; LIMA-FILHO, 2009). Tais modificações, baseadas em políticas de educação, sob o amparo da globalização, passaram a inserir valores mercantis na educação superior, reorganizando o funcionamento desse nível de ensino, caracterizando-o como formado por instituições profissionais, empresariais e competitivas. Dessa forma, estas passaram a ser compreendidas não apenas como locais de socialização do saber e de produção de ideias e reflexões, mas como ambiente produtor de força de trabalho (LOPES, 2006; OLIVEIRA, 2004).

No cotidiano dessas instituições, passam a prevalecer processos de precarização do trabalho docente, caracterizados fortemente por contratos com ausência de muitos direitos trabalhistas e sem qualquer estabilidade, além de profundas mudanças na rotina das atividades de ensino, pesquisa e extensão (BOSI, 2007).

A precarização do trabalho é definida por Alves (2007) como "[...] a explicitação da precariedade como condição ontológica da força de trabalho como mercadoria [...] é síntese concreta da luta de classes e da correlação de forças políticas entre capital e trabalho" (ALVES, 2007, p. 115). Esse processo, nessa perspectiva, inclui dimensões objetivas e subjetivas e, em 
termos amplos, consolida-se, no cotidiano laboral, como perda dos direitos garantidos à classe trabalhadora, envolvendo processos de flexibilização, desregulamentação e precarização social do trabalho (DRUCK; FRANCO, 2011).

No caso específico do trabalho docente no ensino superior, processos de precarização do vínculo e das condições de trabalho sempre foram características comuns no setor privado - desde a constituição, ele é marcado por essas características -, no entanto, em anos mais recentes e de forma acentuada, esses processos também atingiram as grandes universidades públicas, onde se proliferaram as (sub)contratações temporárias de professores, que passaram a ser remunerados, em algumas situações, por horas-aula ministradas. Esse processo tem desencadeado dificuldades e limitações para os docentes e para a própria dinâmica da instituição, pois intensifica o regime de trabalho, aumenta o sofrimento subjetivo dos docentes, fragiliza a mobilização coletiva das associações e aprofunda o individualismo (MANCEBO, 2007). Essa prática vem sendo utilizada como uma das soluções encontradas para o funcionamento das universidades, tendo em vista a redução das verbas orçamentárias.

Como consequências desse processo, algumas dessas instituições destacam cortes que afetam o custeio de diversas atividades essenciais, que incluem serviços terceirizados, água, luz, telefone, dentre outros. O Quadro 1 apresenta dados sobre os ajustes efetuados em algumas universidades públicas. 
Quadro 1 - Valores de cortes orçamentários divulgados pelas universidades e implicações dessas intervenções, Brasil, 2015

\begin{tabular}{|c|c|c|}
\hline Instituições & $\begin{array}{c}\text { Cortes em valores } \\
\text { para o ano } 2015 \\
\text { (R\$) }\end{array}$ & Implicações \\
\hline $\begin{array}{l}\text { Universidade } \\
\text { Federal do } \\
\text { Pará (UFPA) }\end{array}$ & 50 milhões & $\begin{array}{l}\text { Redução no orçamento } \\
\text { de capital em } \\
\text { aproximadamente 50\%; } \\
\text { redução na verba de } \\
\text { custeio em R\$ } 15 \text { milhões } \\
\text { dos R\$ } 154 \text { milhões que } \\
\text { estavam orçados. }\end{array}$ \\
\hline $\begin{array}{l}\text { Universidade } \\
\text { Federal de } \\
\text { São Paulo } \\
\text { (UNIFESP) }\end{array}$ & 25 milhões & $\begin{array}{l}\text { Redução de investimentos } \\
\text { em projetos, obras, } \\
\text { acervos, equipamentos } \\
\text { e mobiliários, dentre } \\
\text { outros bens de capital da } \\
\text { universidade. }\end{array}$ \\
\hline $\begin{array}{l}\text { Universidade } \\
\text { Federal de } \\
\text { Santa Maria } \\
\text { (UFSM) }\end{array}$ & $\begin{array}{l}\text { Na UFSM, a reitoria } \\
\text { divulgou cortes de } \\
10 \% \text { para custeios } \\
\text { e em torno de } 47 \% \\
\text { nos cortes para } \\
\text { investimentos. }\end{array}$ & $\begin{array}{l}\text { Dificuldades no custeio da } \\
\text { universidade, que incluem } \\
\text { o pagamento de água, luz, } \\
\text { telefone, terceirizados, } \\
\text { dentre outros. }\end{array}$ \\
\hline
\end{tabular}

Fonte: SILVA, 2015, p. 25.

Nota: quadro adaptado pelos autores. 
Na Universidade Federal da Bahia (UFBA) e na Universidade Estadual de Feira de Santana (UEFS), por exemplo, constatouse resultados semelhantes aos descritos no Quadro 1. A Pró-Reitoria de Planejamento da UFBA assinalou que os recursos do governo não acompanham o aumento das despesas, desencadeando deterioração nas instalações físicas, manutenção de equipamentos e falta de insumos. As consequências podem ser observadas nas condições de trabalho e saúde desfavoráveis, gerando sobrecarga para o quadro docente, além dos riscos de violência pessoal e riscos ocupacionais diversos (LEMOS, 2011).

Dessa forma, assiste-se no país, ao longo das últimas décadas, ao enxugamento orçamentário destinado às universidades públicas, gerando condições inadequadas, redução do quadro de funcionários e cortes nos investimentos que congelam e/ ou reduzem os salários. Enfim, medidas que as obrigaram a buscar fontes alternativas de recursos (PIRES, 2004).

Cabe, no entanto, salientar, por outro lado, que, também nos últimos anos, houve investimentos significativos no aumento do número de universidade públicas no Brasil, especialmente no interior, em todas as regiões; portanto, ocorreu aporte financeiro nas instituições pertencentes ao governo. $O$ Programa de Apoio a Planos de Reestruturação e Expansão das Universidades Federais (REUNI), criado pelo Decreto no 6.096/2007, foi responsável por impulsionar essa destinação de recursos para as instituições federais, seja na expansão (novas universidades) seja na ampliação das existentes (ANDES, 2007). 
Segundo o Relatório da Comissão Constituída pela Portaria no 126/2012 (BRASIL, 2012), no período de 2003 a 2010, o número de universidades federais aumentou de 45 para 59 (incremento de $31 \%$ ) e de 148 campi para 274 campi/unidades (aumento de $85 \%$ ). Com relação à expansão e à interiorização desse nível de ensino pelo país, o número de municípios com universidades passou de 114 para 272, aumento de $138 \%$. Ou seja, houve, concretamente, aporte considerável na alocação de recursos para a educação pública superior. No entanto, esse aporte, pelo esquecimento histórico e pelo subfinanciamento crônico da educação no país, não foi suficiente para sustentar e ampliar os ganhos proporcionados por esse processo, assistindo-se, especialmente nos últimos anos, a situações de profunda crise financeira nas instituições públicas de ensino superior no Brasil.

Dado o agravamento dessa situação, coube às instituições buscar, constantemente, financiamentos provenientes de recursos externos, o que promoveu e incentivou a competição pelos editais das agências de fomento e/ou financiamentos de iniciativa privada (LEMOS, 2011).

Adicionalmente, por conseguinte, coube ao docente o papel de protagonista das transformações, o que desencadeia alterações significativas no processo de trabalho, ou seja, o exercício da docência passa a contemplar um pool de atividades que ultrapassaram as funções formativas convencionais do professor (LEMOS, 2011). 


\section{PERFIL DO DOCENTE UNIVERSITÁRIO NA CONTEMPORANEIDADE: O TRABALHO DOCENTE MERCANTILIZADO}

Frente a esse novo cenário de mercantilização, o ensino superior surge como campo do setor terciário, com foco na prestação de serviços a partir da regulação conduzida pelo mercado, para assegurar, assim, certas características mercantis ao "produto final" (conhecimento para acumulação e manutenção do sistema capitalista) (PIRES, 2004, p. 263).

Desse modo, fatores como o crescimento econômico, as políticas de desenvolvimento, o avanço tecnológico e a automação da produção fizeram surgir uma dinâmica de trabalho na qual estão inseridos elementos como a alta competitividade, o desemprego, a instabilidade ocupacional e a elevada valorização do aperfeiçoamento, representando as novas configurações assumidas pelo mercado. Assim, o cotidiano das universidades e a prática docente se veem atingidos pela organização produtivista emergente (CAMPOS; LOPES; FREITAS, 2004; MANCEBO, 2007).

Com isso, o perfil do docente e das exigências a que ele precisa atender envolve novas atribuições: o professor agora é responsável não apenas pela sala de aula e pelo desenvolvimento de pesquisas, mas também deve preencher inúmeros relatórios e formulários, emitir pareceres, captar recursos para viabilizar a atividade que realiza e proporcionar condições estruturais para o ambiente de trabalho em que se encontra, ou seja, passa a ser responsável por prover as próprias condições de trabalho (MANCEBO, 2007). 
Nesse processo, assiste-se à presença do fenômeno denominado intensificação do trabalho. Tal quadro abrange inúmeras categorias profissionais, em diversos países, e é definido como o aumento do grau de intensidade do trabalho, por meio do maior dispêndio de energia (PINA et al., 2014). Um dos aspectos que compõem o processo de constituição da intensificação do trabalho gira em torno do aumento do ritmo de trabalho, fator presente no cotidiano docente, alicerçado pelas múltiplas demandas que restringem o tempo, pelo aumento do volume de atividades e pela sobreposição de tarefas (ASSUNÇÃO; OLIVEIRA, 2009).

Por essa via, passou a prevalecer no cotidiano dos docentes universitários, a incorporação de novas exigências, expondo o profissional a um modelo gerencial de produtividade contínua, sob um sistema de trabalho competitivo, que gera sobrecargas físicas e mentais na tentativa de atender às constantes demandas do sistema capitalista (ARAÚJO et al., 2005; LOPES, 2006; OLIVEIRA, 2004).

Dessa maneira, cabe ao docente, imerso em uma instituição regida pela lógica mercantil, avaliada por índices de produtividade e pensada para ser flexível e voltada diretamente para o mercado do trabalho, adequar-se a um perfil operacional estruturado por estratégias e programas de eficácia organizacional (CHAUÍ, 2001).

No bojo dessas discussões, é possível pensar em um diálogo entre o novo arranjo do capitalismo, intermediado pela intensificação do trabalho, com os conceitos elaborados por Marx sobre a extração da mais-valia. Assim, acredita-se que, no contexto atual, o aumento da mais-valia resulta da obtenção 
de maior quantum de trabalho no mesmo intervalo de tempo, pela ampliação do produto-valor global e pela manutenção do valor absoluto da força de trabalho. No cerne desse novo modelo, a pressão exercida para aumentar a quantidade de produção tem-se concretizado como um imperativo na organização do trabalho docente nas universidades (BOSI, 2007).

Essa dinâmica tem representado, no cotidiano do trabalho docente, não apenas o "adestramento" ao padrão de produção vigente, mas também uma necessidade de viabilizar as condições para a realização dessa produção, já que, institucionalmente, os meios de produção acadêmicos permanecem concentrados e/ou disponibilizados para setores do conhecimento que conseguem converter ciência e tecnologia a serviço do capital. Vale frisar que a prática docente, no que tange à pesquisa, tem-se materializado em um crescimento expressivo da produtividade acadêmica, cujo objetivo encerra-se no próprio ato produtivo, isto é, fazer-se e sentir-se produtivo. Dessa forma, os professores ganham notoriedade pela inserção na pós-graduação, por número de orientações realizadas, artigos e/ou livros publicados e, principalmente, por bolsa de produtividade em pesquisa que conseguem adquirir e manter constantemente (BOSI, 2007).

Com isso, o docente passa a ser avaliado com base em indicadores de capacidade produtiva, transformando-se, portanto, em empresário intelectual, por ter que conviver, quase exclusivamente, com critérios quantitativos em detrimento dos qualitativos. Desse modo, o profissional se vê imerso em um movimento extremamente rápido de transformação do 
próprio cotidiano de trabalho, no qual o essencial é encaixarse em um sistema competitivo de produção (CAMPOS; LOPES; FREITAS, 2004; LOPES, 2006).

\section{REPERCUSSÕES NA SAÚDE DO DOCENTE}

Um dos aspectos cruciais que foram modificados no cotidiano do trabalho docente, frente às mudanças citadas, diz respeito à relação dele com o tempo, constatada não somente com base na intensificação e/ou na pressão sobre a atividade, destinada ao alcance dos parâmetros de produção acadêmica crescente, mas também na ampliação do uso do tempo que o professor despende com o trabalho. Dessa forma, os profissionais passaram a se submeter, no dia a dia, à nova lógica de arranjo temporal, caracterizada por uma jornada laboral intensiva e extensiva. Esta última, facilitada pela introdução das novas tecnologias eletroeletrônicas, como e-mail, notebooks, tablets e smartphones, que acompanham os profissionais para além do ambiente de trabalho (MANCEBO, 2007). Como consequência, diminuiu-se o tempo do docente para efetuar, com mais tranquilidade o seu trabalho, atualizar-se profissionalmente e também para direcionar parcela do seu tempo para o lazer e convívio social (CARLOTTO; CÂMARA, 2007).

Por conseguinte, o docente passa a conviver com condições de trabalho que atuam como estressores, responsáveis por diversas situações de desgastes físico, psíquico e emocional, que podem levar a doenças ocupacionais. Tais situações contemplam insatisfações e/ou constrangimentos aos quais esses trabalhadores são expostos ao longo da história profissional, dentre os quais, destaca-se pressão do tempo, 
problemas de relacionamento com os colegas e/ou com a administração, ameaças verbais e físicas provenientes dos discentes, dentre outros. Somado a isso, os docentes ainda são cobrados a adaptar-se às condições sociais, econômicas, tecnológicas e à demanda para se manterem continuamente atualizados diante da rápida transformação do conhecimento científico (FREITAS; CRUZ, 2008).

No Brasil, ainda são poucosos estudos sobre a saúde do professor quando comparado com trabalhadores de outras profissões (ARAÚJO; GRAÇA; ARAÚJO, 2003; ARAÚJO; CARVALHO, 2009). Nesse campo, dois estudos pioneiros, realizados na década de 1990, podem ser destacados. O primeiro, sobre a saúde mental dos professores de ensinos fundamental e médio em todo o país, abrangeu 30.000 professores e revelou que $26 \%$ dos docentes apresentavam exaustão emocional caracterizada pela desvalorização profissional, baixa autoestima e ausência de resultados percebidos no trabalho desenvolvido (CODO, 1999). No segundo estudo, envolvendo amostra representativa dos professores da rede particular de ensino de Salvador (total de 573 professores), as condições de trabalho negativas mais referidas foram esforços físicos elevados $(78,8 \%)$, exposição à poeira e ao pó de giz (62\%) e fiscalização contínua do desempenho (61,9\%). Além disso, as queixas mais frequentes de saúde foram dor de garganta, dor nas pernas, dor nas costas, rouquidão e cansaço mental. A prevalência de distúrbios psíquicos menores foi de 20,3\% (SILVANY-NETO et al., 2000).

Com relação à prevalência de queixas de doenças entre os docentes, realizou-se uma investigação na UEFS que destacou que $72,6 \%$ dos profissionais referiram apresentar pelo menos 
uma queixa de doença. Dentre as queixas de doenças mais frequentes, estavam àquelas relacionadas ao uso intensivo da voz, à postura corporal adotada no exercício da atividade profissional, à saúde mental e à exposição à poeira e ao pó de giz. As queixas mais expressivas relacionadas ao uso intensivo da voz foram: dor na garganta $(20,2 \%)$, rouquidão $(18,5 \%)$ e perda temporária da voz (5,3\%). Quanto à exposição à poeira e ao pó de giz, os docentes destacaram a presença de manifestações clínicas, como: rinite $(26,6 \%)$, alergia respiratória $(21,1 \%)$ e irritação dos olhos (13,5\%). Os problemas associados à postura corporal mais referidos pelos professores foram: dor nas costas $(30,8 \%)$, dor nas pernas $(28,3 \%)$ e dor nos braços $(16,7 \%)$. Além disso, na esfera psíquica, as queixas de maior prevalência relacionadas à saúde mental foram: cansaço mental $(44,0 \%)$, esquecimento (20,3\%), nervosismo (18,5\%) e insônia $(14,1 \%)$ (ARAÚJO et al., 2005).

De modo semelhante, realizou-se um estudo com 257 docentes da UFBA, sendo constatado que $24,8 \%$ dos professores referiram dor de garganta, $43,5 \%$, rouquidão, $22,6 \%$, perda temporária da voz, e $12 \%$ mencionaram terem sido diagnosticados com calo de corda vocal. No que tange aos problemas osteomusculares, $18,8 \%$ referiram sentir dor nos braços, $36,1 \%$, dor nas pernas, $37 \%$, dor nas costas, e $7,8 \%$ relataram terem sido diagnosticados com lesão por esforço repetitivo/distúrbio osteomuscular relacionado ao trabalho (LER/DORT). Observou-se, ainda, que o trabalho docente com maiores exigências (em termos de volume e de extensão no tempo) estava associado às prevalências mais elevadas de queixas de doença (WERNICK, 2000). 
Investigação para verificar as relações entre o processo de trabalho docente, as condições sob as quais ela se desenvolve e o possível adoecimento dos professores foi conduzida em uma universidade federal do Centro-Oeste do país, entre os anos de 2007 a 2008. Os resultados mostraram que os docentes apresentaram exaustão emocional, considerando-se a elevada manifestação de sintomas, tais como nervosismo, estresse, cansaço mental, esquecimento, insônia, dentre outros. Os dados obtidos permitiram afirmar que os depoimentos analisados constituem importantes indicativos sobre como os processos de trabalho interferem na saúde de professores (LIM; LIMA-FILHO, 2009).

Quanto à percepção negativa sobre a saúde, essa foi também evidenciada por estudo realizado com professores de universidades comunitárias no estado de Santa Catarina. Tais resultados destacaram predomínio de sentidos atribuídos a vivências relacionadas ao sofrimento no trabalho, associadas à elevada carga de atividades, que gerava exaustão física e mental e insegurança quanto ao contrato. Ademais, o estudo apresentou, dentre os fatores que contribuem para as vivências de sofrimento referidas pelos docentes, o desgaste provocado pela grande jornada e/ou carga de trabalho, o medo e a insegurança relacionados aos contratos precários e as relações hierarquizadas e competitivas no contexto organizacional (COUTINHO; MAGRO; BUDDE, 2011).

Aspectos ligados à organização do processo de trabalho, discutidos na perspectiva da intensificação do trabalho, e implicações no modo de vida e na saúde de docentes do ensino público superior foram investigados em pesquisa conduzida 
em uma universidade pública federal do Sudeste do país, entre 2009 e 2010. Dentre os resultados apresentados, destacou-se que a maioria dos docentes qualificou o trabalho que realizava como precário, sobretudo quanto à infraestrutura material, relatou trabalhar sob forte exigência para atingir as metas de produtividade (essa sendo apreciada basicamente como publicação científica) e relataram extensão da jornada de trabalho para o espaço doméstico. No que tange aos aspectos relacionados à saúde, parte significativa dos entrevistados apresentou queixas, sendo predominantes aquelas de ordem psicoemocional e/ou psicossomática (BORSOI, 2012).

A percepção da experiência do trabalho docente em cursos de saúde foi objeto de investigação em uma universidade federal da região Norte do Brasil. A maior parte dos docentes relatou sentimentos de vulnerabilidade e desgaste, principalmente em aspectos psicoemocionais relacionados a pressões por produtividade no trabalho, uso excessivo da voz, conflitos interpessoais com outros docentes, estresse e sintomas cardiovasculares, cansaço, dentre outros. Apesar de o exercício profissional ter sido identificado como fonte de estabilidade, realização pessoal e financeira, os docentes destacaram a precariedade e a sobrecarga de trabalho como fatores que tendiam a induzir ao sofrimento e ao adoecimento (LAGO et al., 2015).

Essas constatações ratificam a premissa de que o sistema capitalista transformou o trabalhador em um verdadeiro escravo do tempo, cujo cotidiano não inclui mais disponibilidade temporal para lazer, socialização, atualização ou descanso suficiente, como recompensa, ainda padece ao 
receber um salário indigno, incompatível com as horas de dedicação ao trabalho ou com a qualificação que apresenta. Assim, "o núcleo" do problema não gira, exclusivamente, em torno da pressão a que o trabalhador está submetido, perante as condições de trabalho, mas em torno da dificuldade, cada vez maior, que ele encontra em dedicar tempo para recarregar as energias e cuidar da própria saúde (JUNHO, 2015).

O trabalho realizado nesses moldes tem suscitado preocupação crescente com o desenvolvimento humano no que diz respeito à qualidade de vida, mesmo reconhecendo-se que os avanços da medicina e da tecnologia possibilitaram ao homem viver muito mais tempo do que podia há anos passados. Como a qualidade de vida inclui a possibilidade de usufruto do tempo livre para o prazer, o lazer, as relações sociais e familiares, a expansão dos compromissos e demandas profissionais para o tempo que deveria ser dedicado a essas atividades tem impactos importantes no cotidiano das pessoas (CAMPOS; LOPES; FREITAS, 2004). Adoecimento, afastamento frequente das atividades laborais em função de problemas de saúde e abandono da profissão são indicadores de comprometimento da qualidade de vida no trabalho. Esses apontamentos têm sido observados com tendência crescente entre docentes no Brasil, da educação infantil ao ensino superior (ARAúJO; CARVALHO, 2009), o que demanda atenção e adequado dimensionamento das consequências e dos fatores determinantes desse processo.

O uso do tempo livre para fins de descanso, lazer, atualização e qualificação na realização das atividades de trabalho é possível a partir da reformulação das políticas educacionais, tendo em 
vista a necessidade de rompimento do desenho instituído nas universidades, que prima por uma "academia dinâmica produtivista/consumista" (CAIAFA, 2000, p. 196).

Assim, seria possível materializar a redução da carga horária de trabalho docente e, consequentemente, promover o aumento de tempo livre. Dessa forma, os professores teriam mais acesso à realização de atividades mais prazerosas, bem como poderiam desfrutar de outras atividades capazes de elevar o compartilhamento cotidiano da vida e das relações sociais, elementos importantes para a obtenção da qualidade de vida e de bem-estar (CAMPOS; LOPES; FREITAS, 2004).

Apesar das evidências das características desvantajosas atuais do trabalho docente, a pluralidade de problemas de saúde associados às condições precárias de trabalho e à intensificação deste, análises mais amplas e aprofundadas sobre essa temática ainda são algo que merece atenção, considerandose que, no contexto atual, os agravos à saúde manifestam-se de diversas formas e podem ser facilmente identificados pelos inúmeros acidentes de trabalho, pelo aumento dos casos de absenteísmo por LER/DORT e pela crescente ocorrência de transtornos psíquicos.

\section{CONSIDERAÇÕES FINAIS}

A problemática envolvendo condições de trabalho e seus impactos na saúde dos professores universitários, após a crise do capital e as sucessivas políticas neoliberais, tem sido consequência da reconfiguração na atividade docente, tendose em vista o processo de mercantilização do ensino superior. 
Assim como outras instituições sociais, as universidades passaram a atender às necessidades produtivistas e aos interesses do capital.

Nesse cenário, os docentes passaram a conviver com um ambiente de trabalho precarizado, alicerçado pela lógica empresarial. Diante das novas configurações assumidas pelas instituições, coube ao professor encontrar estratégias de enfrentamento frente às pressões externas, oriundas do enxugamento orçamentário, dos baixos salários, das demandas extraclasses, dentre outros. Algumas dessas estratégias consistem em levantar recursos financeiros junto às diversas agências de fomento, para a aquisição de materiais e equipamentos necessários ao desenvolvimento do ensino, da extensão e da pesquisa. Ou seja, nesses contextos, cabe ao docente prover as próprias condições de trabalho, bem como gerenciá-las. As consequências desse novo modelo produtivista estão relacionadas com a intensificação do trabalho, levando a situações de sobrecarga, de estresse e de competição.

É sabido, na literatura, que a forma como se estruturam as condições de trabalho desempenha papel crucial no processo saúde-doença ocupacional. Assim, com a redução orçamentária destinada às universidades e a subordinação dos professores à lógica do mercado, cria-se um novo perfil docente, o docente "corredor", ou seja, aquele sujeito que se insere na corrida incessante da produção científica, por intermédio da elaboração e da publicação de artigos e da submissão/obtenção de recursos financeiros para os projetos de pesquisa ou de infraestrutura institucional. Dessa forma, a 
saúde e o uso do tempo para o lazer e o descanso passam a ser predicados raros no cotidiano desse profissional.

As discussões que problematizem o trabalho docente nas particularidades que ele possui podem oferecer elementos para um pensar crítico acerca das novas configurações assumidas no ambiente de trabalho e no cotidiano do profissional. Assim, as reflexões levantadas neste ensaio poderão subsidiar a construção de novos processos e metodologias que permitam analisar criticamente o processo de atividade docente, bem como criar estratégias de enfrentamento das doenças ocupacionais e de possibilidades para ampliação dos aspectos humanos no trabalho, de modo que possa contribuir, na realização cotidiana, para o desenvolvimento pleno das capacidades e habilidades humanas.

\section{REFERÊNCIAS}

ANDES, S. N. As novas faces da reforma universitária do governo Lula e os impactos do PDE sobre a educação superior. Cadernos ANDES, Brasília: ANDES, n. 25, p. 1-41, ago. 2007.

ALVES, G. Dimensões da reestruturação produtiva: ensaios de sociologia do trabalho. 2. ed. Londrina: Praxis; Bauru: Canal 6, 2007.

ARAÚJO, T. M.; CARVALHO, F. M. Condições de trabalho docente e saúde na Bahia: estudos epidemiológicos. Educação \& Sociedade, 2009, v. 30, p. 427-449, 2009.

ARAÚJO, T. M. et al. Mal-estar docente: avaliação de condições de trabalho e saúde em uma instituição de 
ensino superior. Rev. baiana saúde pública, v. 29, n. 1, p. 6-21, 2005.

ARAÚJO, T. M.; GRAÇA, C. C.; ARAÚJO, E. Occupational stress and health: contributions of the Demand-Control Model. Ciência \& Saúde Coletiva, v. 8, n. 4, p. 991-1.003, 2003.

ASSUNÇÃO, A. Á.; OLIVEIRA, D. A. Intensificação do trabalho e saúde dos professores. Educação \& Sociedade, v. 30, n. 107, p. 349-372, 2009.

BRASIL. Ministério da Educação. Análise sobre a expansão das universidades federais 2003 a 2012. Relatório da Comissão Constituída pela Portaria noㅡ 126/2012. Brasília, 2012. Disponível em: <http://www. anped11.uerj.br/2013-analise_expansao_universidade_ federais_2003_2012.pdf>. Acesso em: 12 mar. 2016.

BORSOI, I. C. F. Trabalho e produtivismo: saúde e modo de vida de docentes de instituições públicas de ensino superior. Cadernos de Psicologia Social do Trabalho, v. 15, n. 1, p. 81-100, 2012.

BOSI, A. de P. The precarization of the teaching work in higher education institutions in Brazil over the last 25 years. Educação \& Sociedade, v. 28, n. 101, p. 1.5031.523, 2007.

CAIAFA, J. Nosso século XXI: notas sobre arte, técnica e poderes. Rio de Janeiro: Relume Dumará, 2000.

CAMPOS, M. B. L.; LOPES, R. H. B.; FREITAS, C. M. S. O professor universitário: um estudo sobre atividade acadêmica e tempo livre. Rev. Universidade e Sociedade, v. 14, n. 34, p. 67-74, 2004. 
CARLOTTO, M. S.; CÂMARA, S. G. Predictors of Burnout Syndrome in teachers. Psicologia Escolar e Educacional, v. 11, n. 1, p. 101-110, 2007.

CHAUÍ, M. DE S. Escritos sobre a universidade. São Paulo, SP: Editora UNESP, 2001.

CODO, W. (Org.). Educação: carinho e trabalho. Petrópolis, RJ: Vozes; Brasília: Confederação Nacional dos Trabalhadores em Educação: UnB, Psicologia Trabalho, 1999.

COUTINHO, M. C.; MAGRO, M. L. P. D.; BUDDE, C. Entre o prazer e o sofrimento: um estudo sobre os sentidos do trabalho para professores universitários. Revista Psicologia - Teoria e Prática, v. 13, n. 2, 2011. Disponível em: <http://editorarevistas.mackenzie.br/index.php/ ptp/article/view/3031>. Acesso em: 18 jan. 2016.

DRUCK, G.; FRANCO, T. O trabalho e precarização social - Trabalho, precarização e resistências: novos e velhos desafios. Caderno $C R H$, v. 24, número especial, p. 9-13, 2011.

FREITAS, C. R.; CRUZ, R. M. A integração de cadeias produtivas com a abordagem da manufatura sustentável. In: XXVIII ENCONTRO NACIONAL DE ENGENHARIA DE PRODUÇÃO, 2008. Anais.. Rio de Janeiro: ABEPRO, 2008.

JUNHO, Y. E. B. DE P. O tempo nosso de cada dia roubado. EBR - Empresa Brasil de Revistas Ltda, São Paulo, SP, 2015.

LAGO, R. R. et al. Perception of the teaching profession at a university in northern Brazil. Trabalho, Educação e Saúde, v. 13, n. 2, p. 429-450, 2015. 
LEMOS, D. Teaching jobs in federal universities: tensions and contradictions. Caderno $\mathrm{CRH}$, v. 24, número especial, p. 105-120, 2011.

LIM, M. de F. E. M.; LIMA-FILHO, D. de O. Condições de trabalho e saúde do/a professor/a universitário/a. Ciências \& Cognição, v. 14, n. 3, p. 62-82, 2009.

LOPES, M. C. R. "Universidade produtiva" e trabalho docente flexibilizado. Estudos e Pesquisas em Psicologia, v. 6, n. 1, p. 35-48, 2006.

LUXEMBURG, R. The accumulation of capital. London and New York: Routledge, 2003.

MANCEBO, D. Professor's work: subjectivity, "superimplication" and pleasure. Psicologia: Reflexão $e$ Crítica, v. 20, n. 1, p. 74-80, 2007.

MANCEBO, D.; LOPES, M. C. R. Trabalho docente: Compressão temporal, flexibilidade e prazer? Rev. de Educação Pública, v. 13, n. 24, p. 138-152, 2004.

MANCEBO, D.; MAUÉS, O.; CHAVES, V. L. J. Crise e reforma do Estado e da Universidade Brasileira: implicações para o trabalho docente. Rev. Educar, n. 28, p. 37-53, 2006.

MASCARENHAS, M. S. Transtornos mentais comuns entre docentes do departamento de saúde da Universidade Estadual de Feira de Santana. 2010. Monografia (Graduação em Enfermagem) - Departamento de Saúde, Universidade Estadual de Feira de Santana, Feira de Santana, Bahia, 2010. 
NECKEL, F.; FERRETO, L. E. Avaliação do ambiente de trabalho dos docentes da Unioeste campus de Francisco Beltrão. Revista Faz Ciência, v. 8, n. 1, p. 183-204, 2006.

OLIVEIRA, D. A. Restructuring the teaching profession: precarization and flexibilization. Educação \& Sociedade, v. 25, n. 89, p. 1.127-1.144, 2004.

PINA, J. A. et al. Work intensification and workers' health: a theoretical approach. Revista Brasileira de Saúde Ocupacional, v. 39, n. 130, p. 150-160, 2014.

PIRES, V. Ensino superior e neoliberalismo no Brasil: um difícil combate. Educação \& Sociedade, v. 25, n. 86, p. 263-268, abr. 2004.

SILVANY-NETO, A. M. et al. Condições de trabalho e saúde dos professores da rede particular de ensino de Salvador. Rev. Baiana de Saúde Pública, n. 56, p. 20-31, 2000.

SILVA, S. P. da. O aprofundamento da reforma do estado e o redirecionamento do ensino superior. Rev. Universidade e Sociedade, n. 56, p. 20-31, 2015.

WERNICK, R. Condições de saúde e trabalho dos docentes da Universidade Federal da Bahia, Salvador-BA. 2000. Dissertação (Mestrado em Saúde Coletiva) - Instituto de Saúde Coletiva, Universidade Federal da Bahia, Salvador, Bahia, 2000.

\section{ABSTRACT}

The sociopolitical and economic changes intensified from the 90 s produced several changes in the teaching work. Its organization model has required higher productivity and even more specialized professional qualification (work 
intensification), thus stimulating the emerging of new attributions. Such assignments have negatively reflected on these professionals' health. Within this framework, the faculty began to live in environments based on the business logic, with bad working conditions, leading them to situations of overworking, stress and competition, besides weakening the interpersonal relations and crippling the adequate use of free time. Such aspects spoil the faculty's life quality. In this context, and understanding that the way working conditions are set has a crucial role in the occupational health-disease process, the present paper aims to highlight the commodification process in the Brazilian universities and its effects on teachers' health.

Keywords: Health. Faculty. Higher Education. Commodification.

\section{Daniel Alberto Santos e Santos}

Mestrando em Saúde Coletiva pela Universidade Estadual de Feira de Santana (UEFS). Possui graduação em Psicologia pela Faculdade de Tecnologia e Ciências (FTC). Especialista em Saúde Mental com Ênfase em Dependência Química. Pesquisador integrante do Núcleo de Epidemiologia (NEPI-UEFS).

danielalbertopsi@yahoo.com.br

\section{Caroline Almeida de Azevedo}

Mestranda em Saúde Coletiva pela Universidade Estadual de Feira de Santana (UEFS); especialista em Psicologia do Trânsito (UNIP); graduada em Psicologia pela Faculdade de Tecnologia 
e Ciências (FTC), Feira de Santana-Bahia, Brasil; pesquisadora integrante do Núcleo de Epidemiologia (NEPI-UEFS).

carolineaazevedo@hotmail.com

\section{Tânia Maria de Araújo}

Possui graduação em Psicologia pela Universidade Federal de Minas Gerais, mestrado em Saúde Comunitária pela Universidade Federal da Bahia, doutorado em Saúde Pública pela Universidade Federal da Bahia e pós-doutorado na University of Massachusetts. Professora titular da Universidade Estadual de Feira de Santana (UEFS).

araujo.tania@uefs.br

\section{Jorgana Fernanda de Souza Soares}

Bacharel, licenciada (licenciatura plena) e mestre em Enfermagem pela Universidade Federal do Rio Grande (FURG). Doutora em Saúde Pública com área de concentração em Epidemiologia pela Universidade Federal da Bahia (UFBA). Professora adjunta no Departamento de Medicina Preventiva e Social da Faculdade de Medicina da Bahia - Universidade Federal da Bahia e colaboradora do Programa de PósGraduação em Saúde Coletiva da Universidade Estadual de Feira de Santana.

jfss_rs@hotmail.com 